\title{
La historia en palabras historiadores, profesores y políticos
}

ANA ZAVALA

Instituto Universitario Centro Latino Americano de Economía Humana, Montevidéu, Uruguai

\section{RESUMEN}

Este trabajo indaga el gesto de la versión - palabra escrita, hablada, actuada- que atraviesa la aventura social del pensamiento histórico en los últimos doscientos años en el mundo europeo-occidental. Es la idea que la historiografía ofrece múltiples versiones del acontecer humano a lo largo del tiempo lo que habilita el juego de las otras versiones que se le superponen. La versión destinada a la enseñanza permite ver las maneras de (no) asumir esa noción de versión respecto a la relación entre la historia y el acto de enseñarla. Por esa razón, el sentido social y político/ideológico de la enseñanza de la historia a todos dentro de una escuela para todos, es también una versión de la historia y de la historiografía. Demandada por el análisis de la práctica de la enseñanza, una última versión da cuenta de la historia, de la historiografía y de su enseñanza. El trabajo concluye destacando la importancia de separar los campos del análisis y de los cambios en las prácticas (historiográficas/de enseñanza).

\section{PALABRAS CLAVE}

didáctica de la historia; análisis de la práctica de la enseñanza; espesor discursivo. 


\title{
HISTORY IN WORDS: HISTORIANS, TEACHERS AND POLITICIANS
}

\begin{abstract}
This article interrogates the version's modes - from the written, spoken or acted word - which have gone across the social adventure of the historical thinking along the past two hundred years in the Western European world. Historiography offers multiple versions of the human experience throughout the times, which enables dealing with other superposed versions. Its teaching version allows seeing the ways of assuming (or not) such notion of the relation between history and the history teaching action. Therefore, the social meaning and political/ideological meaning of history teaching for all in schools for all is also a version of history and historiography. Required by the analysis of teaching practice, one last version accounts for history, historiography and their teaching. This work stresses the relevance of keeping away the fields of analysis and of changes in historiographical and teaching practices.
\end{abstract}

\section{KEYWORDS}

didactics of history; analysis of teaching practice; discursive density.

\section{A HISTÓRIA EM PALAVRAS: HISTORIADORES, PROFESSORES E POLÍTICOS}

\section{RESUMO}

Este trabalho interroga o movimento da versão - palavra escrita, falada, em ato que atravessa a aventura social do pensamento histórico nos últimos duzentos anos no mundo europeu ocidental. A ideia é de que a historiografia oferece múltiplas versões do acontecer humano ao longo do tempo, o que habilita o jogo de outras versões que se sobrepõem. A versão destinada ao ensino permite ver maneiras de (não) assumir essa noção a respeito da relação entre a história e o ato de ensiná-la. Por essa razão, o sentido social em estreita relação com o político/ideológico do ensino da história para todos numa escola para todos é também uma versão da história e da historiografia. Demandada pela análise da prática de ensino, uma última versão dá conta da história, da historiografia e de seu ensino. $\mathrm{Na}$ conclusão, o trabalho destaca a importância de separar os campos da análise e das mudanças nas práticas (historiográficas/de ensino).

didática da história; análise da prática do ensino; espessura discursiva. 
La bistoria nunca es segura.

Certeau, 2005, p. 11

\section{A MODO DE INTRODUCCIÓN}

Antes que nada, tengo que decir que un título como este necesita más de una aclaración previa, empezando por el uso que en él se hace de la palabra "historia". Si el artículo estuviera escrito en alemán, "historia" estaría seguramente refiriéndose a Geschichte, en su sentido primario y más arcaico del acontecer humano, ése que luego es objeto de algún tipo de relato, de análisis, de investigación, para finalmente ser objeto de estudio, de conocimiento, de aprendizaje... En efecto, es de las palabras de las que están compuestos los relatos y los análisis de los que me ocuparé en este artículo, lo que me lleva a una segunda aclaración: en realidad, las palabras son en este caso los textos.

Por otra parte, también hay algo que aclarar acerca de los dos puntos [:] en mitad del título. Gramaticalmente hablando establecen una igualdad entre las dos partes del mismo, o más bien respecto de la noción de puesta en palabras que se desdobla en tres versiones posibles de la historia: la de los historiadores, la de los profesores y la de los políticos que actúan tanto sobre su producción como sobre las distintas formas de su difusión, entre las cuales la enseñanza tiene históricamente en un lugar de privilegio. Como se verá a lo largo del trabajo, asumo que cada instancia de puesta en palabras constituye de por sí una versión, tanto de lo que pasó como de lo que uno sabe que pasó porque lo leyó en algún libro de historia.

Naturalmente que las cosas no son tan simples como podría deducirse del enunciado del título, pero -transgresión paratextual flagrante- hay veces en las que uno no puede o no debe explicitar todo en el nombre del trabajo so pena de volverlo definitivamente incomprensible. A lo que me refiero es a que, por ejemplo, la enseñanza de la historia posiblemente sea más una versión de la historiografía que de la historia en tanto acontecer del pasado, al cual los profesores mayormente acceden leyendo libros de historia.

Por otra parte, sería difícil negar que una gran parte de la historiografía es a su vez una versión de otra historiografía, porque alcanza con leer cualquier libro de historia para ver o entrever las menciones a otros historiadores, en tanto autoridades o en tanto -justamente-versiones cuestionadas acerca del mismo tema. Finalmente, en lo referente al mandato político, las formas de pensar su relación con la historia y la historiografía, y naturalmente también con la enseñanza, no me parece que se puedan aislar de la noción de versión entendida -a dos puntas- como opción por una forma de comprender tanto al pasado como al trabajo de los que lo investigan, pero también entendida como generadora de una ortodoxia ideológica (es decir, una versión) que marca el uso correcto, el abuso, y el mal uso del saber histórico para los ciudadanos.

Este artículo trata entonces de la posibilidad de pensar analíticamente la naturaleza y las relaciones existentes entre los distintos contextos discursivos que se 
ocupan de decir, interpretar y conceptualizar los eventos del pasado, cada uno con su público y según su época. Para eso no me queda más remedio que pasar por los territorios de la semiótica y de la hermenéutica (pagando los respectivos peajes), antes de llegar al terreno de la filosofía de la historia que será de alguna manera nuestra primera tierra firme. La mención al trabajo analítico de los profesores de historia, es necesario decirlo, adscribe el trabajo al campo de la didáctica de la historia, posiblemente el único contexto en el que la globalidad del artículo tiene sentido, debiendo ser entonces su verdadera tierra firme.

\section{EN TORNO A LOS SENTIDOS DE LA ACCIÓN, EL HABLA Y LA ESCRITURA}

Lo que yo sé, yo lo creo.

Wittgenstein, 1975, p. 62

\section{UN TEJIDO DE TEXTOS}

Para empezar, podríamos poner las cosas de esta manera: un "documento histórico” dice -a su manera- lo que pasó. Un historiador escribe lo que pasó y algo acerca de lo que pasó según se desprende de la lectura que hace del documento que dice lo que pasó, remitiendo al documento, texto y autor cuando es posible. Un profesor da su clase diciendo en voz alta lo que los historiadores que ha leído dicen por escrito acerca de lo que pasó, citando o glosando en sus obras textos de otros historiadores, novelistas, poetas, documentos administrativos anónimos y textos con autor reconocido. Si se trata de un estudiante, lo hará -en voz alta o por escrito- tratando además de recuperar más o menos fielmente lo que su profesor ha dicho en clase. En efecto, en este contexto prácticamente nadie-salvo en algunos casos el autor de eso que llamamos "documento" o de un historiador que enseñe sobre su propia investigación- está autorizado si no remite de alguna manera a lo que otro dijo, ya se trate de un historiador en su libro, de un profesor de historia en su clase o de un alumno el día del examen de historia.

En definitiva de lo que estamos hablando es que -tanto en materia de historiografía como de enseñanza de la historia- los textos escritos y hablados sobre los que ambas se soportan son ostensiblemente intertextuales. Es posible que la propia obviedad de esta afirmación haga que su lugar en el análisis no sea siempre el de la primera fila, porque de hecho no lo es. Sin embargo deberíamos poder admitir sin mayor problema que el abordaje de las cuestiones hermenéuticas que hacen al corazón de este trabajo -estructurado de hecho en torno a la noción de versión- no puede violentar la naturaleza intertextual de todo lo que uno tiene delante de los ojos para hacer como si todo el tiempo se tratara de textos simples y primarios (del tipo de: es un hermoso día de otoño), en lugar de textos en los cuales precisamente el espesor discursivo es con toda probabilidad una clave de primer orden para la comprensión/interpretación de los mismos. 
Sucede, sin embargo, que los trabajos sobre intertextualidad no se han ocupado mucho de la historiografía ni menos lo han hecho en relación a las clases de historia. Nacieron para entender la literatura ${ }^{1} \mathrm{y}$ de alguna manera se ampliaron en forma general hacia el plano del análisis del discurso como herramienta teórica más allá de géneros y estilos (y por supuesto de los campos disciplinares específicos). De todas formas, aquí lo que interesa es lo que la dimensión intertextual de un discurso como el de la historiografía o el de la clase de historia aporta para la comprensión de ambos. En otras palabras, visto de esta manera, nos damos cuenta que nunca hay que entender uno de estos textos como si fuera estrictamente uno solo.

En el libro de historia o en la clase de historia siempre hay más de un texto, sedimentados, incrustados, entretejidos uno con otro, que sin embargo tienen el aspecto de un discurso singular: el libro de historia ha sido escrito por un autor y es la voz de un profesor la que se oye en la clase. Es cierto que hay momentos en que la copresencia del otro texto es reconocible en tanto aparece citado, entrecomillado, o referido directamente, pero también es cierto que no siempre es así y eso es precisamente lo que me interesa destacar. En todo caso, esto nos sugiere que la producción de sentido para un texto, y por lo tanto la versión que podamos dar de él (a su vez un texto referido a otro texto), tendría que estar siempre atenta al juego intertextual que hay en él.

Como veremos, lo interesante es entonces que no solo hay versiones superpuestas correspondientes a textos leídos y reescritos sucesivas veces, sino que además en el cuerpo de un texto la producción de sentidos (comprensión e interpretación) tiene como distintos registros en función de las dimensiones intertextuales que lo atraviesan.

\section{DECIR LO QUE SÉ: ENTRE ENTENDER LO QUE PASÓ Y ENTENDER LO QUE LEÍ}

Hubo un tiempo en que la hermenéutica soñaba con proporcionar las reglas para comprender los textos aún mejor que sus propios autores como decía Friedrich Schleiermacher (1987, p. 120). Después, las potestades interpretativas de los lectores fueron ganando terreno hasta que por fin un día Roland Barthes (1987a, p. 75-84) proclamó la muerte del autor (a manos del lector, o mejor dicho de los teóricos de la lectura), mientras que Michel de Certeau (2000, p. 177-190) sostenía que la lectura era como una cacería furtiva en el texto del otro. Paralelamente, la confianza referencial que al menos en el mundo europeizado se acostumbraba a depositar en el lenguaje (en la palabra y particularmente en la escritura) tropezó con los juegos de lenguaje de Ludwig Wittgenstein (1999, p. 7 y 23), o con la idea de Hans-Georg Gadamer (1977, p. 367) de que cada vez que uno comprende, 10

1 Solo a modo de presentación, la referencia a autores como Gérard Genette (1982), Julia Kristeva (1969), Mijail Bakhtine (2003) y Roland Barthes (1973) resulta ineludible, aún si la idea es analizar otro tipo de discursos que los que dieron origen a esos trabajos. 
bace de otra manera. Por otra parte, Julia Kristeva (1969, p. 13) ya había sugerido que había una larga serie de prácticas significantes estratificadas y acumuladas que se correspondían a la capacidad de significancia del texto, y entonces, el mundo de los textos nunca más volvió a ser el mismo.

Este asunto nos permite resignificar el trasfondo del título del trabajo, según el cual, por ejemplo, la historiografía y la clase de historia podrían ser simplemente versiones del acontecer o de los textos que relatan, analizan, describen... Deberíamos darnos permiso para pensar que la historiografía y la clase de historia -al igual que la literatura- acaban siendo siempre la versión de algún lector, historiador, profesor de historia o alumno de primer año, que no (de)muestra su posesión/comprensión hasta que habla o escribe su versión acerca de lo que leyó en un libro o escuchó decir al profesor, mientras otro (el profesor o el alumno) lo escucha o lo lee, tratando de entenderlo... Desde este punto de vista, la forma en que Julia Kristeva (idem, p. 145) combina el tema del texto, su destinatario y los otros textos a los que está vinculado en dos ejes -uno que llama "vertical" y que vincula textos y otro que llama "horizontal" que representa el vínculo de la comunicación entre autor y lector- resulta enormemente pertinente a los fines de este trabajo. Nos aleja de concepciones del texto que prácticamente lo asimilan a un objeto material, sin trazas de su propia creación ni del evento de su comunicación a otros. Como herramienta de comprensión y análisis de los eventos acontecidos en los contextos de práctica de la enseñanza de la historia es enormemente potente, más aún cuando esta misma herramienta es pertinente para el análisis del propio trabajo historiográfico.

Es por esta razón que me parece importante poner el acento en la existencia de una larga cadena de interpretaciones, es decir de versiones de los acontecimientos y los textos que los dicen, que no entrelaza solamente distintos y sucesivos lectores, sino que alterna los actos de lectura con otras prácticas discursivas, algunas orales y otras escritas. Creo que el hecho de tratarse esencialmente del estudio sobre un objeto definitivamente ausente, se convierte en un detalle de la mayor relevancia a los efectos de comprender la complejidad de la relación entre el texto leído (o escuchado, si es una clase) y los eventos relatados e interpretados en él.

A mi manera de ver, lo interesante es animarse a considerar un escenario en el que se entrecruzan una dimensión intertextual con una que implica per se una estratigrafía de versiones acumuladas. Creo que es todavía un desafío mayor darse cuenta que este escenario lo comparten-cada uno a su manera- los historiadores, los profesores de historia y también los alumnos de todos los niveles, en tanto todos son lectores/intérpretes y productores de textos ya sea escritos, ya sea hablados. De hecho, historiadores, profesores y alumnos pasamos la mayor parte del tiempo profesional interpretando y produciendo textos escritos y hablados que no pueden no recoger partes de otros textos, en la modalidad que sea. Es justamente esto lo que -para este caso- reconfigura y da espesor a la propia noción de versión, que termina siendo como caleidoscópica.

En los siguientes apartados, y partiendo de estas consideraciones que me parecen ineludibles, abordaré la cuestión de la historiografía como versión del 
pasado inevitablemente entretejida con el escenario social y político en el que se mueve. De esta manera, la versión del Estado y la sociedad serán abordadas en simultáneo o en paralelo con las cuestiones más específicas del trabajo historiográfico. En un segundo momento, iré a las consideraciones más específicas de la enseñanza de la historia, dentro de las cuales el proyecto social y político es seguramente mucho más visible que lo que lo es en el plano de la producción historiográfica. En este punto, como veremos, la cuestión no es la versión, sino más bien la no-versión (versión al fin) que suponen los proyectos laicos, republicanos, democráticos, etc.

En un tercer momento, la versión que me ocupará será la que los profesores individualmente considerados hacen de sus propias clases, incluyendo por lo tanto a la vez, historia, historiografía y práctica de la enseñanza de la historia. La versión de la historiografía y de la historia que constituye la clase en la que han sido enseñadas se la lleva el tiempo, pero existe siempre la posibilidad de atraparla en un relato que la (re)presente y trabajar sobre ella como se trabaja sobre los "documentos" históricos en referencia a un objeto definitivamente ausente. Es lo más cerca que podemos estar de la enseñanza de la historia en tanto práctica de la enseñanza, así que no va a ser aquí que lo dejemos de lado.

\section{UN LIBRO DE HISTORIA DICE EL SABER DE UN HISTORIADOR}

\section{La historia es lo que hacen los historiadores. Prost, 2010, p. 13}

\section{PENSAR EN EL HACER DE LOS HISTORIADORES}

También hubo un tiempo en que la historia (es decir, la historiografía) parecía destinada a decirnos la verdad acerca de lo que había sucedido en el pasado (al decir de Leopold von Ranke: "wie es eigentlich gewesen ist"), gracias al trabajo que los historiadores hacían en base a los testimonios que habían sobrevivido a su propio tiempo. Después, las cosas cambiaron. En algún momento, alguien se dio cuenta de que la escritura de la historia era, ella misma, un producto de su tiempo y de su autor al igual que los textos antiguos en los que basaba su estudio. Así, un día Reinhart Koselleck (2010, p. 27) dijo que la historia, tal como la conocemos hoy en día, empezó a ser como muy pronto a fines del siglo XVIII, y Michel de Certeau (1993) escribió un libro diciendo que la escritura de la historia es una producción del tiempo y del lugar, además de haber dicho que nunca es segura (2005, p. 11). A todo esto, Roland Barthes (1987b, p. 173-177) dijo que el discurso de la historia en el fondo no era más que una ilusión referencial, producto del efecto de lo real y Hayden White (1992, p. 74) agregó que -escritura acerca de un objeto ausente- la historiografía está muy lejos de poder marcar con toda seguridad sus diferencias capitales con el discurso de ficción. Después de esto, las alusiones a la 
opacidad esencial de los subalternos basadas en la idea del tout-autre derrideano hechas por Gayatry Spivak (1998), no tendrían que sorprender a nadie.

Dicho esto, no tiene sentido tomar una ruta argumentativa para mostrar que cada libro de historia constituye una versión particular de los acontecimientos que relata y analiza, que es propia de su autor, que es hijo de su tiempo, pero también de un partido de su tiempo, partido social, ideológico, religioso, epistemológico, científico... Por esto, lo que me interesa en este artículo es más bien mostrar cómo el hecho de que el trabajo historiográfico constituye una versión de los hechos del pasado se articula en un contexto de versiones todas en torno de lo mismo: el pasado y su relevancia en el presente. Es pues a eso que dedicaré esta parte del trabajo, a tratar de desgranar la noción de versión para enfatizar el sentido que tiene, precisamente en cuanto versión, tanto desde lo epistemológico como desde lo social y político, incluyendo naturalmente el acto de su enseñanza.

Entonces, creo que en principio conviene dar cuenta de la superposición de versiones de distinta índole que terminan en el libro de historia, porque no todas son lo mismo ni importan de la misma manera en este trabajo. Empezando por lo más básico, tendríamos que aterrizar en los rudimentos de la teoría del lenguaje, o de la acción, o en sus diversas combinaciones, para tratar de ver de qué manera la primera escritura (posiblemente la del documento antiguo) dice la acción. Pero como hay de por medio una acción de escribir ese texto, ya son dos acciones que se entrelazan y producen sentido en la medida en que ambas -la de escribir y la de hacer aquello que alguien pone en palabras- están lingüísticamente mediadas. Las dimensiones prelingüísticas y definitivamente extra-lingüísticas de las acciones escapan -afortunadamente- a los intereses de este trabajo.

Lo que no escapa, es la idea de que el texto escrito no es una traducción literal (en el sentido de algo idéntico e invariable) del pensamiento o del saber de un sujeto respecto de la cosa que está siendo puesta en palabras, así sea un relato simple de un evento simple, un relato más complejo de un evento más complejo o la puesta en palabras de un trabajo de análisis que se ha desarrollado a lo largo de décadas. Escribimos siempre una versión de nuestro saber, y podríamos -siempre- escribir otra. Simplemente un eslabón más entre el texto escrito y los acontecimientos referidos y analizados en él, de los cuales no puede ser, naturalmente, más que una versión. Ya Vygotsky (1995, p. 177) a comienzos de los años treinta había considerado la posibilidad de hacer una diferenciación entre lo que pensamos, en tanto habla interna, lo que decimos y lo que ponemos por escrito.

A los efectos de este trabajo interesa especialmente su idea de que el habla interna es de naturaleza predicativa (no es necesariamente gramatical) en tanto la escritura es todo lo opuesto: necesita apoyarse en las formas gramaticales en tanto no goza de las condiciones del habla interna ni tiene al destinatario del texto frente a sí para combinar las palabras con los gestos del cuerpo, incluido el énfasis de la voz. De esta manera estamos obligados a considerar la analogía entre las cosas pensadas/ sabidas, las que se dicen por escrito y las que se comunican por vía oral, pero no podemos ir más allá de eso. Lo que sí podemos hacer es considerarlas todas como 
versiones superpuestas de un evento, del texto que lo dice, de lo que yo sé, o de lo que recuerdo haber visto, leído, escuchado...

Entrando con más propiedad al terreno de la filosofía de la historia en tanto análisis de la producción historiográfica, interesaría tener en cuenta el hecho de que, por la propia naturaleza de su trabajo, algunos autores consideran que lo que más le importa a un historiador no es decir las cosas que pasaron, o lo que dicen los textos antiguos, sino más bien algo acerca de ambos y para muchos autores esto es un punto crucial. Es por esto, por ejemplo, que Koselleck insiste en que "la histórica" - es decir, la condición de posibilidad de cualquier "historia"- no puede nunca terminar siendo considerada como un subcaso de la hermenéutica $(1997$, p. 88). Dicho de otra manera, los textos medievales no hablan de la Edad Media, ninguno de los documentos del siglo III romano habla acerca de la crisis de ese siglo, nadie hablaba en el Uruguay a fines del siglo XIX ni de la modernización rural ni del disciplinamiento... "Escribir la historia de un período significa hacer enunciados que no pudieron ser hechos nunca en ese período", dice Koselleck (idem, p. 92), y luego agrega que la histórica remite a procesos "que no están contenidos en ningún texto como tal, sino que más bien provocan textos".

Entonces lo que tenemos es por un lado un trabajo de corte hermenéutico, que genera una versión del/los texto/s leído/s (y que de alguna manera podría colindar con la crítica literaria, el análisis genético, etc.), y por otro uno de corte historiográfico que construye un sentido para el conjunto de los hechos de una época, que se materializan en la producción de un texto (historiográfico), que es intertextual al menos en relación a los otros textos leídos por su autor. Es intertextual en la forma, pero al mismo tiempo contiene dos tipos de construcción de sentido (es decir, dos versiones, dos frutos del trabajo de interpretación, en el sentido de "tal como yo lo entiendo..."): un sentido para los textos leídos, y otro para el conjunto de los eventos con los cuales esos textos se relacionan (que puede ser tanto su contenido - la batalla- como el evento de su producción -la práctica de emitir comunicados militares- como también puede ser la propia forma de la narración). Por otra parte, el trabajo de construcción de sentido para esos eventos, implica en el caso del análisis una cierta provisión de respuestas para unas ciertas preguntas con las cuales se inició el trabajo, inscritas todas ellas en alguna megacategoría, como época tal, crisis cual, factor de aquello, naturaleza social, ideológica, etc. del asunto, que es la que ha guiado a ese historiador al estudio de ese tema, y a la búsqueda de esos textos, de la naturaleza que sean.

En cierta forma y casi sin percibirlo, hemos atravesado una frontera que abre otras perspectivas para las consideraciones de la versión que nos ocupan en este trabajo. Investigar el pasado y escribir libros de historia (lo mismo que dar clase de historia) es una acción -y podríamos hablar de práctica, si quisiéramos complicar un poco más las cosas-. En tanto acción humana intencional tiene para su actor algún sentido, y si no, o bien no la haría o la haría de otra manera. Y como ese sentido que el actor de la acción le da a lo que hace forma parte de la acción, ésta es -en muchos sentidos- una versión de sí mismo... ya sea que pelee 
la batalla, que escriba el parte, que escriba la historia, que la enseñe o que tenga que mostrar su conocimiento en un examen... Esta constitución recíproca de sí y de la acción discursiva (Ricœur, 2006, p. 138) no puede estar ausente en un escenario en el cual todo el mundo es productor de texto, acerca de los eventos o acerca de los dichos de otros, de los historiadores a los alumnos, pasando por los profesores...

Un libro de historia, al igual que una clase de historia, es la versión de muchas cosas, más allá del cruce de intertextualidad y superposición de versiones textuales que hemos mencionado anteriormente. Sin explayarme demasiado en esto solo quisiera consignar, tal vez desde el sentido común, que los historiadores son historiadores porque les gusta la historia y les gusta investigarla, investigan los períodos que les interesan, y lo hacen desde la óptica que les parece la mejor, en la que se sienten más cómodos, la que pueden defender mejor. Así como los argumentos no son los padres de las convicciones sino sus hijos, tanto las versiones de los textos como las del pasado son posiblemente mucho más el fruto de una pasión que el de la aplicación de una fórmula o una metodología y esto da una nueva óptica a la noción de versión tal como la estamos manejando en este artículo.

Desprendidos de la compulsión de objetividad o de neutralidad respecto de su objeto de estudio, algunos historiadores lo han expresado con claridad y con naturalidad: "Estas motivaciones intervienen en la elección del objeto (relativo a un interés religioso) o e la finalidad del estudio -dice Michel de Certeau (1993, p. 145). Y luego explicita: "Por una parte se hace historia religiosa porque se es cristiano [...] puesto que ya no se puede hacerla a lo cristiano", y para concluir que "por otra parte [...] se movilizan los resultados al servicio de la creencia" (idem, ibidem). Años antes Lucien Febvre (1970, p. 37) había dicho a los estudiantes, en su primer día en la carrera de historiadores: "Me gusta la historia. No sería historiador si no me gustara".

En una línea que tal vez no les resultara extraña a estos historiadores, podríamos remitir sin dificultad a toda la bibliografía relativa a la cuestión del rapport au savoir, que ilumina con mucha claridad la relación de quien quiere ser historiador o profesor de historia con el saber histórico. ${ }^{3}$ También podríamos sin duda, poner un pie en la cuestión de la imaginación como componente -a veces innombrable- del trabajo de los historiadores, y por extensión de los profesores de historia y de sus alumnos. En un terreno en el que lo que se sabe es por definición algo que "ya no es" ni volverá a ser, el lugar de la imaginación en la restitución al presente de un objeto definitivamente ausente - pero pensable- no puede ser

2 Ver además: Jean-Marie Barbier, "Problématique identitaire et engagement des sujets dans les activités”, en Jean-Marie Barbier, Étienne Bourgeois, Guy Villers y Mokhtar Kaddouri (Éds.), Constructions identitaires et mobilisation des sujets en formation, Paris, L'Harmattan, 2006, p. 15-64.

3 Ver, por ejemplo: Jacky Beillerot, "Le rapport au savoir ", en Nicole Mosconi, Jacky Beillerot y Claudine Blanchard-Laville (Dir.), Formes et formations du rapport au savoir, Paris, L'Harmattan, 2000, p. 39-57. 
dejado de lado. Hayden White (1992, p. 74) se pregunta: “`No es posible que la cuestión de la narrativa en cualquier discusión de la teoría histórica sea siempre finalmente una cuestión sobre la función de la imaginación en la génesis de una verdad específicamente humana?" .

Tal vez he abierto demasiado el abanico de opciones en relación a la diversidad de componentes involucrados en el trabajo de producción/ interpretación/restitución de textos en materia historiográfica o de enseñanza de la historia. Si no quedara más que la idea de que se trata de un asunto realmente complejo y abordable desde múltiples ángulos, sería buena cosa.

\section{OBJETOS AUSENTES, OBJETOS SOÑADOS, OBJETOS IMAGINADOS...}

La historia que enseñamos día a día en nuestras clases, la que leemos en los libros, la que tiene sentido para nosotros, es heredera de una tradición relativamente joven. Koselleck (1997, p. 15) la sitúa en el último tercio del siglo XVIII, Michel de Certeau (1993 p. 10) un poco antes, y Hanna Arendt (1972, p. 77) más o menos por la misma época... De todas formas, y más allá de la alusión precisa a algunos historiadores, el consenso interpretativo que rodea a la existencia de un vínculo entre esta nueva forma de hacer historia y los estados nacionales, liberales, burgueses que se fueron afirmando todo a lo largo del siglo XIX es realmente fuerte. Ya vendrán otros que verán las cosas de otra manera.

Stathis Gourgouris, (1996, p. 4) afirma que a diferencia del trabajo que puede hacer un psicoanalista a partir de un sueño para construirle sentido, el trabajo de la nación consiste también en ponerla en palabras (para prevenir el olvido), pero más bien para reafirmar un sentido que la preexiste. Gourgouris entiende que la fuerza operativa de la nación es precisamente una fantasía social que se adhiere a lo invisible e intangible que hace de la historia algo sensible: "Deseo dejar en claro que la elaboración onírica de la nación [Nation's dream-work] no significa intentar interpretar la nación como sueño sino más bien suponer que hay algo de sueño detrás de cada inscripción histórica" ${ }^{4}$ Por su parte, Michel de Certeau (1993, p. 35) dice que "la historia es sin duda nuestro mito. Combina lo pensable con los orígenes, según el modo como una sociedad se comprende", mientras que Benedict Anderson (1998) habla de comunidades imaginadas...

La idea de que la Nación es un sueño de Stathis Gougouris, como la de que es una comunidad imaginada, de Benedict Anderson, como la de Ernest Renan (1882) de que la Nación está hecha también con un poco de olvido... junto posiblemente con la de David Lowenthal (1998) de que el pasado es un país extraño y la de Paul Ricœur (2003, p. 516) de que es necesario aculturar a las jóvenes generaciones para enfrentar la inquietante extranjeridad del pasado, y tal

4 Remito aquí a una amplia bibliografía en torno a los usos públicos del pasado, que abarca desde los trabajos de Suzanne Citron, Christian Amalvi y Pierre Nora, en Francia, hasta los de Eric Hobsbawm o Benedict Anderson en el ámbito angloparlante, y también los de José Rilla y Carlos Demasi en Uruguay. 
vez algunas otras, todas son de recibo en este trabajo en la medida en que desde distintos ángulos tienden a fortalecer la idea de que el presente desde el que se busca al pasado, lo encuentra, y lo pone en palabras, tiene mucho que ver con el resultado de la empresa. Que esa empresa, como dice Roland Barthes (1987b), haya tenido a bien intentar sistemáticamente no hacer foco tanto en los rastros del autor que hay en ella como en las razones sociales y políticas de su existencia es otra cosa, y también importa considerarla.

Poner la nación en palabras ha sido "históricamente" tarea de muchos, pero sin duda ha sido la tarea de los historiadores y de los profesores de historia. Podría repasar aquí una amplísima bibliografía de distinta procedencia y encontraría más o menos lo mismo: el estudio del pasado nos dice quiénes somos, por qué somos así, de dónde venimos, nuestros orígenes, nuestras raíces, y acaba así explicando el presente (y en muchos casos por qué habría que cambiarlo).

A los efectos de este trabajo, lo que importa considerar es que hay alguna razón política y en definitiva ideológica-que desemboca necesariamente en una versión- para recordar el pasado y hacer de él una historia, una historiografía y una enseñanza (con la expectativa de un aprendizaje, pero más bien de una formación social, cívica, política, o ideológica...). Lo que interesa en realidad no es que distintos autores, provenientes de distintas orientaciones y de distintas épocas y lugares den respuestas diferentes a la pregunta de por qué esto es así, sino que la pregunta pueda ser formulada: ¿por qué estudiar y enseñar cosas referentes al pasado de la humanidad, de nuestra cultura o de nuestro propio país/ nación? Esto nos lleva entonces -y por otro camino- a la noción de versión en tanto interpretación (y por lo tanto una entre otras posibles) del pasado: versión de los textos, versión de los hechos, versión de la historiografía, versión de uno mismo, versiones entrelazadas con textos entrelazados intertextualmente, versiones múltiples de su razón de ser...

$\mathrm{Y}$ sin embargo es desde aquí que podemos pasar a un terreno en el cual justamente la idea de versión termina siendo hereje y políticamente incorrecta. Freud (1919) diría que es algo que está en el plano de lo ominoso. En efecto, el Estado y las autoridades de la enseñanza tienen por lo general bastante poca disposición a lidiar discursivamente con todo esto en forma razonable, y en general prefieren entender las cosas de maneras más simples, más prácticas -y en el fondo necesarias- en relación al mantenimiento de un pacto de origen ${ }^{5}$ que se supone invisible, impensable e inmune al paso del tiempo. Kaës (1989) hablaría sin duda de un pacto de denegación, transmitido casi inconscientemente de generación en generación...

$5 \quad$ Al respecto, ver Ana Zavala (2012, p. 21-23). 


\title{
EN EL LIMBO DE LA NO-VERSIÓN: LA PRETENSIÓN DE QUE SE ENSEÑE HISTORIA MÁS ALLÁ DE (ALGUNA) HISTORIOGRAFÍA
}

\author{
Los excesos del sentido histórico que sufre el presente \\ son intencionadamente promovidos, fomentados y utilizados. \\ Nietzsche, 2006, p. 139
}

\section{LAS CIENCIAS DE LA PATRIA}

Hay muchos autores ${ }^{6}$ que resaltan la vecindad temporal de la afirmación de los estados liberales-nacionales a lo largo del siglo XIX, el advenimiento de un tipo de historiografía con fuerte interés en los temas "nacionales" y la aparición de una materia escolar llamada "historia", lo cual les permite tejer algunos vínculos causales entre todos estos acontecimientos. En algunos países como en Francia, por ejemplo, la enseñanza de la historia aparece ligada a la de la geografía y a la educación cívica, reafirmando con más claridad el vínculo entre un tipo de Estado (nación y régimen) y la enseñanza de conocimientos que contribuyeran tanto a su justificación y como a su buen funcionamiento. Remito, posiblemente como el mejor ejemplo, a las consideraciones de Pierre Nora en Les lieux de mémoire respecto del rol jugado por la obra de Ernest Lavisse en la consolidación nacional y cívica de Francia. Para Nora la historia de Francia constituye el fruto del trabajo de Lavisse en el plano institucional, político, profesional, metodológico e intelectual sobre la Nación en tanto "marco ecuménico para las sucesivas legitimidades de la vida de un pueblo" en el cual "la Historia de Francia será la de la Nación realizada" (1997, p. 859). Tal vez sin un radio de acción tan expandido y estructurado, todos los países que se consideran a sí mismos naciones tienen, con seguridad, su Ernest Lavisse, encarnado en uno o en varios intelectuales, pensadores, historiadores... encargados de elaborar el o los sucesivos relatos de la Nación, tan historiográficos como políticos e ideológicos, al ritmo de su propio tiempo.

De todas formas, lo que me interesa en este punto es ver cómo estas consideraciones se entienden con la noción de versión que la historiografía puede dar respecto del pasado, sea o no relevante para la construcción de la identidad nacional, el sentimiento patriótico, la formación ciudadana, y otras finalidades no-cognitivas con las que carga la enseñanza institucionalizada de la historia. La presunción de un dominio de lo correcto, y por lo tanto de otro de lo incorrecto, atraviesa de un lado a otro los textos políticos -y también los académicos- referidos a la enseñanza de la historia, partiendo de la base de la existencia de una buena historia (que es

6 La bibliografía de referencia aquí podría ser agobiante. Me limitaré a señalar solamente algunos autores que pueden dar cuenta de la relación entre enseñanza de la historia y fundación de la Nación. Citaré, por ejemplo, a Suzanne Citron (1989; 1991), Ruth Sandwell (2006, particularmente el capítulo 7) y Pilar Maestro (2003, p. 173-222). Merecen también una mención especial los trabajos de Ernesta Zamboni (2003, p. 367-377) y los de Luis Fernando Cerri (2011). 
por lo tanto la que hay que enseñar) y de otra mala, que expresamente no debe ser tenida en cuenta. Partiendo de una lógica bien interesante la mayor parte de las veces la buena historia es tenida por neutral, objetiva y esencialmente "verdadera", mientras que la mala historia es portadora de una interpretación, y es precisamente de ahí que se desprenden sus notas negativas: sesgada, ideológica, proselitista, etc., y en definitiva "falsa".

También es posible que unos Estados acusen a otros, o unos tiempos acusen a otros, de haber enseñado "la mala historia" con fines políticos, sociales, económicos, ideológicos, religiosos, o todo junto. En todo caso, vista de esta manera, la versión correcta no es sino una versión especial, es decir, la que se considera como la verdadera versión de lo que pasó en el pasado, y por consiguiente aquella que por definición no está atravesada por ningún tipo de interés que no sea el de la verdad al servicio de los mejores fines políticos, sociales, religiosos, ideológicos, o todo junto.

Entre varios ejemplos de esta situación, analizaré brevemente un documento producido por el Consejo de Europa, en $1999 .{ }^{7}$ Creo que hay que destacar el hecho de que el Consejo de Europa se ocupe explícitamente del tema de la enseñanza de la historia (y de contragolpe del de la producción historiográfica), generando eventos internacionales, publicaciones y materiales que son puestos a disposición de los profesores (de historia, pero más bien de educación cívica, ciudadana, etc.), pudiéndose descargar gratuitamente de su sitio web en varios idiomas. Por otra parte me parece que el propio contenido de la publicación puede también dar lugar a comentarios interesantes en relación con el tema de este trabajo. Naturalmente, lo primero que llama la atención es justamente la idea de deformación (misuses o détournement) que da lugar al evento y a la publicación.

Luego de haberse preguntado acerca de qué, en la naturaleza misma de la historia, hace que pueda ser sujeto de deformaciones, los participantes han tratado de determinar por quién y por qué la historia es deformada. Han estudiado las modalidades de las deformaciones en toda su diversidad (deformación por negación de una evidencia histórica, por falsificación, por fijación, por omisión,

7 El simposio internacional titulado "Frente a las deformaciones de la historia" (Face aux détournements de l'histoire; Facing misuses of history) dio lugar a la publicación de un libro (versión inglesa: Misuses of history; versión francesa: Détournements de l'bistoire) que estuvo un tiempo disponible en línea, pero ahora ya no lo está. Los libros en versión papel, según figura en la página del Consejo de Europa, están agotados. Ver también: Conseil de L'Europe (1999): Leçons d'bistoires, Le Conseil de L'Europe et l'enseignement de l'histoire (versión inglesa: Lessons in history. The Council of Europe and the teaching of history). En ese año se realizaron dos conferencias internacionales, una en abril (en Andorra) en relación a la cuestión de los manuales de historia, y otra en junio (en Oslo) en relación a las deformaciones de la historia ambas en el contexto del proyecto “Aprender y Enseñar la Historia de Europa del Siglo XX". Las sesiones del simposio de Oslo se abrieron con una conferencia de Georg Iggers acerca de la historiografía del siglo XX, y la relatoría del evento estuvo a cargo de Laurent Wirth, historiador e Inspector General de Educación de Francia en aquel momento. Para un panorama más completo sobre esta cuestión consultar: <http://www.coe.int/t/dg4/education/ historyteaching/default_fr.asp>. 
por pereza o ignorancia, por recuperación...). (Conseil de L’Europe, 2001, p. 7, mi traducción)

En efecto, a lo largo de las más de 150 páginas del libro, la idea de que hay una forma correcta de hacer la historia, pero vulnerable, y que por lo tanto da lugar a manipulaciones malintencionadas (p. 57, entre otras) constituye precisamente lo que no está en discusión. Llama sin embargo la atención el hecho de que los teóricos que apuntan a la dimensión narrativa de la historia, a la subjetividad del historiador, a su compromiso con sus convicciones, etc. están permanentemente mencionados y aludidos. Llama igualmente la atención la manera en que esto se juega en un contexto que atiende particularmente a la tolerancia, a la inclusión, a la diversidad... ${ }^{8}$

Creo que sin ninguna dificultad podemos dar a esta postura el status de versión acerca de la historia, la historiografía y la enseñanza de la historia, una versión que se pretende no ideológica, no ligada a intereses políticos, sociales, económicos, culturales, sino relacionada con todos a la vez y establecida por consenso político, como ortodoxia -legitimada por ese consenso- de lo bueno y lo correcto. Frente a este texto, que tiene eco en decenas de otros trabajos, uno tiene la sensación de que no ha pasado el tiempo, que da lo mismo 1870 que 1920 o 1950 o $1999 .$. No importa lo que los historiadores hagan ni lo que la filosofía de la historia pueda aportar para comprender su trabajo, los Estados siguen siempre esperando de la historia, y sobre todo de la enseñanza de la historia, un buen servicio para el régimen (el que sea), para la sociedad, y para la construcción de un futuro mejor (y a veces merecido, cueste lo que cueste). Las diversas miradas acerca de las condiciones de producción del conocimiento histórico, las variadas y también diversas consideraciones que lo alejan sensatamente del status de ciencia-verdad, parecería que estos efectos o van por otro carril y es como si no existieran. Definitivamente no parecen ser funcionales a una manera de entender los fines políticos de la enseñanza de la historia a todo el mundo.

No quisiera terminar este apartado sin hacer referencia a las posturas que conceden un status epistemológico especial a la historia enseñada distinto del de la historia investigada. La historia que se enseña en las clases no constituye para algunos autores una versión de la historia sino otro tipo de saber. Se refiere a los mismos eventos, pero tiene otra naturaleza. Desde su punto de vista, la historia enseñada está, por ejemplo, hecha por los profesores, siendo su mejor marca precisamente

8 Los ejemplos respecto de la deformación de la historia están en su mayoría en relación con el nazismo, el franquismo, el fascismo y el estalinismo, aunque se advierte que las mentes mal intencionadas -falsos historiadores en definitiva- tienen en los regímenes democráticos un ámbito de acción que obliga a estar doblemente atentos para denunciar su presencia y su acción. Es como si por un lado hicieran cuestión de la manipulación de la historia que pueden hacer los regímenes totalitarios, y por otro la extrañaran en los regímenes democráticos que, libertad mediante, crean un terreno fértil para los que deseen manipular la historia sin tener cómo ser controlados. 
la de liberarse de las imposiciones de la historiografía, siempre cambiantes, y con toda seguridad, se aprende de otra manera.

Proveniente del ámbito francófono, los trabajos de Nicole Lautier dan un poco la tónica de la cuestión. ${ }^{9}$ Tomo la siguiente cita de un trabajo de un trabajo de Crémieux, Audigier y Tutiaux-Guillon (1994), porque me parece extraordinariamente ilustrativa de la postura que quiero mostrar:

Los saberes de referencia sirven aquí para producir otro tipo de saber, ciertamente situado y eventualmente garantido en apariencia por las "autoridades" pero muy diferente de sus orígenes y que se nutre igualmente de otras fuentes. (traducción y subrayado mío) ${ }^{10}$

Sin ser tan explícito en este sentido, en el ámbito anglosajón tienen un lugar destacado los trabajos de Sam Wineburg $(2001)^{11}$ en la medida en que se enfocan en las notas específicas que provienen del conocimiento histórico a la hora de leer, entender, aprender... En el ámbito de la lengua portuguesa tienen un destaque especial algunos trabajos de Marcos da Silva y Selva Guimarães Fonseca (2010, p. 14) $)^{12}$ en tanto enfatizan en la presencia de una cultura escolar relativamente independiente del mundo académico de la producción del conocimiento histórico.

En última instancia habría que llevar la discusión al terreno de la naturaleza de un discurso que es suficientemente análogo a otro, o sea que dice (o habla de) lo mismo pero con otras palabras, en el sentido de que utiliza estructuras discursivas diferentes a las que tenían los textos en los cuales los saberes ahora enseñados fueron antes aprendidos por quien los enseña. Desde mi punto de vista es más fácil argumentar a favor de que se trata de una versión del anterior, que sostener que se trata de otro tipo de saber. Naturalmente, todos hemos escuchado o leído "versiones" de textos historiográficos en las cuales efectivamente parece que sí, que se tratara de algo esencialmente nuevo y diferente (y en general lo denominamos con la palabra "error", por ser una interpretación indefendible). Queda abierta entonces la cuestión de definir al discurso de la enseñanza de un saber aprendido como otro tipo de saber, lo que nos remonta necesariamente a la distinción entre el saber del historiador (en su cabeza) y el que pone en el libro para que los demás tengan conocimiento del mismo.

9 Ver en especial Lautier (1997).

10 Siguen sin duda a Henry Moniot. Ver, por ejemplo: Didactique de l'histoire, Paris, Nathan, 1993.

11 Ver en especial el capítulo 3, titulado: "On the reading of historical texts. Notes on the breach between school and academy" (Wineburg, 2001, p. 63-88). El trabajo de James Loewen, Lies my teacher told me. Everything your American History textbook got wrong, New York, Touchstone, 1996, es provocador, y enormememente revelador de un cierto state of mind en esta cuestión.

12 "Essa foi uma conquista importante porque reafirmou, entre nós, a concepção de que ensinar História nao é apenas repetir, reproduzir conhecimentos eruditos produzidos noutros espaços: existe também uma produção escolar". 
En los hechos zanjar esta cuestión implica necesariamente la referencia a posturas filosóficas e historiográficas que como veremos de inmediato -en consonancia con las apuestas epistemológicas del Estado y buena parte de la Academia respecto de la comprensión de la historia en tanto asunto enseñado- se mantienen a buena distancia de las mismas y no son generalmente de recibo.

\section{A CONTRAPELO}

Hoy en día la mayoría de los programas de historia reflejan con más o menos fidelidad modelos historiográficos que son anteriores al último tercio del siglo XX. Proponer un curso en el estilo de El queso y los gusanos de Carlo Ginzburg, o de la Historia de la sensibilidad de José Pedro Barrán o de La valija del tío Hugo de Raúl Jacob no es -por ahora- pensable. Estas temáticas o estos enfoques tienen, siempre que algún profesor lo quiera, un lugar más bien ornamental en un curso. No hay programas de historia que sean de microhistoria y nunca sabremos a ciencia cierta cuantos cursos hay que sean total o parcialmente de microhistoria (o de otras tendencias actuales de la historiografía, como por ejemplo los estudios de la subalternidad), porque difícilmente sean registrados como tales en las libretas de los profesores. Encuadrados mentalmente en una perspectiva historiográfica y filosófica tributaria de los orígenes de la enseñanza de la historia, para la mayoría de los estudiantes una clase de esas tiene el aspecto de no ser de historia. La idea está reforzada, en muchos casos, por la ausencia o el bajo peso de estos enfoques en las tareas de evaluación.

Hay que reconocer, sin embargo, que una buena parte de la historiografía actual se separa dramáticamente de los modos de hacer y de las temáticas que durante el siglo XIX y la mayor parte del XX le valieron el reconocimiento de los Estados y un lugar en las aulas de la enseñanza básica y obligatoria. Esto augura, tal vez por primera vez, una partición entre la historia/historiografía enseñable y la no enseñable, y crea un escenario incierto respecto de muchas cosas, entre las cuales admitir oficialmente que la historiografía ofrece tan solo una versión de lo que pasó no parece ser la más relevante.

A mi manera de ver el distanciamiento más dramático no refiere estrictamente a la diversidad de las posibles conclusiones historiográficas respecto de un mismo asunto temático, sino más bien a los modos de entender y de hacer historia. Quedaría por saber si estamos simplemente frente a un "retraso" de los modos de pensar la presencia de la historiografía en la enseñanza en relación a las nuevas tendencias de la historiografía y de la filosofía de la historia, o si se trata más bien de un "rechazo". Es verdad que buena parte de esta historiografía ya no es funcional a los distintos cultos nacionales a los cuales la enseñanza de la historia es tributaria: la patria, los héroes, un gran relato que engloba los orígenes, el presente y las expectativas del futuro, la contribución a la consolidación o el mantenimiento de distintas identidades relacionadas con la nación, o con el régimen político, etc. Para muchos es -antes que nada- mucho más difícil de aprender... (y seguramente de enseñar, y de aprender a enseñar). Razón de más. 


\title{
LAS ÚLTIMAS VERSIONES: MI CLASE Y SU RELATO
}

\author{
El relato forma parte de la vida \\ antes de exiliarse en la escritura. \\ Ricceur, 2006, p. 166
}

\section{LA ESCRITURA DE LA VOZ}

El evento predominantemente oral, sonoro, de la clase de historia es en sí mismo etéreo, inasible más allá de su acontecer en el tiempo del aula. Por esta razón también necesita de un soporte lingüístico y textual para perdurar en el tiempo, formar parte de la memoria y tener la posibilidad de ser analizado. ${ }^{13}$ Necesitamos -una vez más- un texto que tome el lugar de eso que ya no es y que no volverá a ser. Volvemos pues a la cuestión de las versiones.

El espesor discursivo del texto que dice mi clase de historia es extraordinario. Es la clase, es la historia que enseñé, es mi proyecto para la clase, es -aún en términos primarios- una valoración del evento, es una producción de sentido, es una teoría de la enseñanza, es la didáctica de la historia. Realmente, merece respeto.

Empecemos entonces por el principio: hay una voz que habla. Habla de lo que uno sabe, de lo que leyó, y también de los textos que están presentes en la clase en forma escrita (en forma de oraciones, de esquemas de pizarrón, etc.). Más arriba hemos hablado de este juego intertextual y de la superposición de versiones que implica: versión del documento, versión de los libros leídos, de las clases escuchadas, versión de mi saber, de mí misma... (y aquí podemos incluir una versión del otro, más claramente presente en el discurso de la clase que en los otros textos que le dan soporte). Lo que interesa aquí es entonces el hecho, que no hemos visto anteriormente, de la escritura transformada primero en lectura y luego en un discurso hablado en un marco institucionalmente configurado. Habíamos visto la lectura transformada en escritura pero no en discurso hablado. Si en algún lugar la noción de versión aplica perfectamente, es aquí, más cuando ese discurso hablado tiene grandes posibilidades de terminar siendo como veremos un texto escrito.

Efectivamente, yo puedo saber muchísimo sobre un tema pero solo tengo cuarenta minutos para hablar delante de/trabajar con 35 alumnos de 12 años, cuya adhesión a la escucha ordenada y silenciosa es bastante relativa. No es lo mismo que tener tres horas-reloj para hablar del mismo tema sentada delante de 12 adultos autoconvocados y amantes de la historia en un curso de posgrado. Sin duda un mismo conocimiento, dos versiones. Es decir dos versiones de mi conocimiento, no dos versiones de la historiografía o de la historia, que son los saberes-objeto que han dado lugar a mis conocimientos. Entiendo que este planteo se podría equiparar a la escritura de un artículo de una carilla para un suplemento de divulgación o

13 Si lo grabamos o lo filmamos, es lo mismo. Miramos el video o escuchamos la grabación, y empezamos a hablar como lo haríamos después de haber visto la clase. También podemos tomar notas, fotografías.... Pero estos vestigios o testimonios no cambian lo esencial de la cosa: hay un texto posterior que es el de la reconstrucción discursiva de la acción que da lugar a los textos del análisis, porque nunca es uno solo. 
un capítulo en un libro, pero lo que me interesa ciertamente enfatizar aquí es la construcción de un discurso "en la urgencia", por llamarlo de alguna manera. Es un discurso que no tiene, como este que estoy escribiendo ahora, la posibilidad de ser releído, corregido, con citas añadidas al pie, con transcripciones incorporadas... Se dice de una vez, y en todo caso se corrige, amplía, retoca, pero siempre sobre la marcha. Lo que ya se dijo no se puede cambiar. Naturalmente siempre existe un plan de clase más o menos minucioso, pero nunca es como una obra de teatro en la que uno sabe palabra por palabra todo lo que ha de decir, incluyendo lo que han de decir los otros actores en escena.

La clase es entonces una nueva versión que se agrega a toda la serie anterior de versiones que hemos visto y hace de su relato algo especialmente espeso en materia discursiva. Por una vez empecemos de atrás para adelante, temporalmente hablando. Estamos leyendo un texto que contiene el análisis de una clase o de un curso de historia. En tanto análisis, es naturalmente un texto diferente del de la clase analizada pero lo contiene y supone un relato anterior en el cual la clase ha sido "contada". ${ }^{14}$ Por otra parte este relato incluye, más o menos explícitamente, un relato anterior a la clase -el del proyecto y el del plan de clase (cuando se los puede diferenciar con claridad) - que en buena medida estructuran la percepción del acontecer de la clase en función de lo que uno esperaba hacer o que sucediera en ella cuando la pensó.

Si se quiere se podría trazar un cierto paralelo con el trabajo de los historiadores: un evento que ya no existe (la clase) re-presentado por un texto (el relato de la clase) y algunos vestigios materiales (fichas de trabajo, fotografías, etc.), otro evento que ilumina su comprensión (el plan de clase), que dan lugar a otro texto que tiene como finalidad construir sentido para ese evento que no necesita relatar en tanto existen otros relatos que lo documentan. ${ }^{15}$

Ahora bien, la clase dice en efecto lo que el profesor que la dicta (la dice) sabe porque lo ha leído en los libros de historia (y también lo ha escuchado en clases de historia). Acabamos de ver que ese discurso de la clase es una versión, en todo el sentido de la palabra, del conocimiento del profesor: versión porque es una interpretación de sus lecturas, y también versión porque es una construcción verbal que dice lo que sabe. A su vez, los libros que ha leído son versiones del pasado y de los textos que los historiadores han leído, los cuales a su vez, son versiones de los eventos de los que dan cuenta. Debe haber pocas cosas con más espesor discursivo y con una dimensión intertextual más compleja.

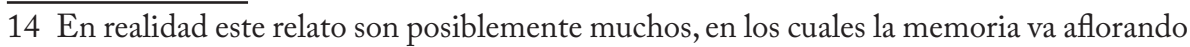
a medida que el análisis la va requiriendo. Nunca se parte de un relato "total" al estilo Funes.

15 Tomo aquí al plan de clase como un relato ficcional de un evento que aún no ha acontecido y que por lo tanto -estrictamente hablando- carece de referente. 


\section{UNA ESCRITURA INVISIBLE}

Sin embargo, la práctica de la enseñanza en tanto práctica parecería que es como invisible. De hecho, la mayor parte de la investigación académica la ha convertido en un objeto inasible, y definitivamente invisible. Por un lado, si hay que estudiar la enseñanza de la historia, la actual o la de antes, el primer impulso es ir a mirar los programas y el segundo, los manuales. En un gesto diferente pero análogo y complementario, también hay muchos trabajos hechos en función de las producciones de los alumnos (desde trabajo de campo con escritos y exámenes hasta entrevistas o pruebas especialmente diseñadas para la investigación). Parecería entonces que la práctica de la enseñanza (de la historia en este caso) no necesita ser contactada directamente puesto que resulta ser tanto la consecuencia necesaria de una causa conocida (el programa) como la causa natural de una consecuencia conocida (el trabajo de los alumnos).

Creo que en efecto lo que sucede es que este objeto es también ideológicamente inasible, porque en el fondo es políticamente incorrecto. Como sea, existe y se puede ver en los relatos y en los análisis que los profesores hacen de sus propias clases. ${ }^{16}$ Permite ver lo que otras investigaciones no ven, y posiblemente si se los mira de cerca y con atención termine desacreditando a más de una. Creo que es posible que el gesto del desconocimiento respecto de los relatos de los profesores del que da cuenta buena parte de la academia sea análogo y se corresponda con el gesto de desconocimiento (más bien de des-reconocimiento) de buena parte de la historiografía contemporánea porque no son funcionales a un modelo de funcionamiento del Estado y de quienes lo respaldan conceptualmente. De todas formas, no por eso deja de existir y en definitiva de dar cuenta de la/s forma/s en que la historiografía y la historia, llegan a las aulas. Cómo salgan de allí, es otro problema que no tiene nada que ver con las maneras en que los profesores analicen sus clases o las planifiquen, incluso en muchos casos tampoco tiene que ver con la forma en que las dicten... Es decir, hay más actores en este juego que no han sido considerados en este trabajo más que lateralmente. En definitiva la última versión de la historia, de la historiografía, del manual y de mi clase es la de mis alumnos.

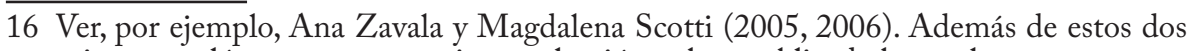
primeros volúmenes, en esta misma colección se han publicado hasta el momento otros seis volúmenes, el último de los cuales estará disponible en julio de 2014. 


\title{
CONCLUSIÓN: ENTENDER, DESPUÉS CAMBIAR
}

\author{
Serán los profesores quienes, en definitiva, \\ cambiarán el mundo de la escuela, entendiéndola. \\ Stenhouse, 1998, p. 2
}

La idea de este trabajo ha sido en cierta forma la de ofrecer un punto de vista poco usual para asuntos que estamos acostumbrados a considerar históricamente, $\mathrm{o}$ pedagógicamente, o didácticamente... Me parece que una mirada desde lo discursivo, lo hermenéutico, lo filosófico, contribuye a darle otra profundidad a un objeto que nunca acabará de ser total y completamente asido.

De todas formas proponer un cambio de mirada no significa proponer una nueva manera de hacer, al menos en lo que refiere a la enseñanza de la historia. El mundo educativo está acostumbrado a que la "manera de entender" lo que sucede actúe como un nuevo figurín de modas indicando cómo hay que vestir en la próxima temporada. Es cierto que la comprensión de lo que uno hace puede tener que ver con la búsqueda de una nueva forma para hacerlo, pero no necesariamente ha de ser así. De hecho hasta podría ser todo lo contrario.

La cuestión de fondo es siempre la de disponer de herramientas de análisis más potentes. Lo es para los historiadores como lo es para los profesores de historia. Herramientas de análisis de los saberes y de las prácticas que tienen que ver con esos saberes, ya sea que los produzcan, los enseñen, o los aprendan (porque los historiadores y los profesores también aprenden, y si no saben no pueden dedicarse ni a hacer la historia ni a enseñarla, ni a analizar las prácticas de ellos o de otros...). Por esto me ha parecido interesante posicionarme tanto como me ha sido posible en lugares de análisis en los cuales la práctica de la historiografía y la de la enseñanza de la historia (y en algunos casos también la de los estudiantes de historia) eran visibles con la misma herramienta de análisis. Una práctica, una lectura, una escritura, un aprendizaje, una construcción identitaria... Naturalmente, hay herramientas que apuntan directo a la especificidad de cada una, pero como también hay de estas otras, me pareció que era una buena oportunidad para trabajar con ellas.

Por otra parte, la idea de integrar al análisis de la práctica de la enseñanza de la historia elementos que provienen de dimensiones históricas, como el entrelazamiento entre la configuración de un modelo historiográfico y uno de enseñanza de la historia profundamente tributarios de una manera de entender el Estado y la Nación, me ha parecido esclarecedora y fructífera. Lo es, a mi manera de ver, a dos puntas: en la medida en que las huellas de lo que considero un pacto de origen entre el Estado, la historiografía y la institucionalización originaria de la enseñanza de la historia tienen hoy en día un lugar importantísimo, pero también en la medida en que la separación entre parte de la producción historiográfica y filosófica en relación a la historia no encuentran lugar en una estructura tributaria del mencionado pacto de origen. Habiendo sido la enseñanza de la historia, casi por definición, una acción destinada a producir efectos más bien políticos, sociales o ideológicos que propiamente cognitivos, estas consideraciones me han parecido 
de recibo, a la hora de entender algunos aspectos del presente y sobre todo de pensar a futuro.

Finalmente, solo decir que me parece que es crucial no dejar pasar ninguna oportunidad, ninguna herramienta potencialmente enriquecedora, ya sea que venga de la lingüística, de la semiótica, del psicoanálisis, de la filosofía del lenguaje, de la acción. Es por eso que en este trabajo me he permitido tomar prestadas herramientas de análisis que no fueron pensadas originalmente para la práctica de la enseñanza de la historia. Sea de donde sea que venga será bienvenida si ayuda a comprender mejor lo que hacemos desde el lugar que lo hagamos. Cambiarlo o tratar de mejorarlo, es siempre un efecto de una comprensión profunda de lo que uno mismo hace, sea político, historiador, profesor de historia o alumno.

\section{REFERENCIAS}

Anderson, Benedict. Comunidades imaginadas. México: FCE, 1998.

Arendt, Hanna. Le concept de l'histoire. In: La crise de la culture. Paris: Gallimard, 1972. p. 58-120.

Bakhtine, Mijail. Estética de la creación verbal. Madrid: Siglo XXI, 2003.

Barthes, Roland. Théorie du texte. In: Roland Barthes. Nouvelle édition revue, corrigée et présentée par Eric Marty. Paris: Ed. du Seuil, 1973. (Euvres complètes, 1972-1976, v. IV)

La muerte del autor. In: El susurro del lenguaje. Más allá de la palabra y la escritura. Barcelona; Buenos Aires: Paidós, 1987a. p. 75-84.

El discurso de la historia. In: El susurro del lenguaje. Más allá de la palabra y la escritura. Barcelona; Buenos Aires: Paidós, 1987b. p. 173-177.

Cerri, Luis Fernando. Ensino de história e consciência histórica: implicações didáticas de uma discussão contemporânea. Rio de Janeiro: Editora FGV, 2011.

Certeau,Michel de. La escritura de la historia. México: Universidad Iberoamericana, 1993. La lectura, una caza furtiva. In: La invención de lo cotidiano. 1 . Artes de hacer. México: Universidad Iberoamericana, 2000. p. 177-190.

La possession de Loudun. Paris: Gallimard, 2005.

Citron, Suzanne. Le mythe national. L'histoire de France revisitée. Ivry-sur-Seine: Les Editions de L'Atelier, 1989.

L'histoire de France, autrement. Paris: Éditions Ouvrières, 1991.

Conseil de L'Europe. Détournements de l'histoire. 2001. Versión inglesa: The misuses of history. Disponibles en: <http://www.coe.int/t/dg4/education/historyteaching/ Source/Projects/DocumentsTwentyCentury/Misuse_fr.pdf $>$. $\langle$ http://www.coe.int/t/ $\mathrm{dg}$ 4/education/historyteaching/Source/Projects/DocumentsTwentyCentury/Misuse en.pdf >. Consultados en: 11 dez. 2009. 
Crémieux, Colette; Audigier, François; Tutiaux-Guillon, Nicole. La place des savoirs scientifiques dans les didactiques de l'histoire et de la géographie. Revue Française de Pédagogie, Lyon: INRP, n. 111, p. 11-23, 1994.

Da Silva, Marcos; Guimarães Fonseca, Selva. Ensino de história hoje: errâncias, conquistas e perdas. Revista Brasileira de História, São Paulo: ANPHU, v. 31, n. 60, p. 13-33, 2010.

Febvre, Lucien. Combates por la historia. Barcelona: Ariel, 1970.

Freud, Sigmund. L'inquiétant. In: SIGMUND FREUD. Paris: PUF, 2002. p. 147-168. (Euvres complètes, 1916-1920, v. XV)

Gadamer, Hans-Georg. Verdad y método. Fundamentos de una hermenéutica filosófica. Salamanca: Sígueme, 1977.

Genette, Gérard. Palimpsestes. La littérature au second degré. Paris: Seuil, 1982.

Gourgouris, S. Dream nation. Enlightenment, colonization and the institution of modern Greece. California: Stanford University Press, 1996.

KaËs, René. Le pacte dénégatif dans les ensembles intersubjectifs. In: Guillaumin, Jean (Éd.). Le négatif, figure et modalités. Paris: Dunod, 1989. p. 101-136.

Koselleck, Reinhart. Histórica y hermenéutica. In: Koselleck, Rienhart; Gadamer, Hans-Georg. Historia y hermenéutica. Barcelona: Paidós, 1997. p. 65-94.

. Historia/historia. 2. ed. Madrid: Editorial Trotta, 2010.

Kristeva, Julia. Semiotiké. Recherches pour une sémanalyse. Paris: Seuil, 1969.

Lautier, Nicole. Enseigner l'histoire au lycée. Paris: Armand Colin, 1997.

Lowenthal, David. El pasado es un país extraño. Madrid: Akal, 1998.

Maestro, Pilar. El modelo de las historias generales y la enseñanza de la historia. In: Carreras Ares, Juan José; Forcadell Alvarez, Carlos (Comps.). Los usos públicos de la historia: ponencias al IV Congreso de la Asociación de Historia Contemporánea. Zaragoza: Marcial Pons Editores, 2003. p. 173-222.

Nietzsche, Friedrich. Segunda consideración intempestiva. Buenos Aires: Libros del Zorzal, 2006.

Nora, Pierre. Les lieux de mémoire. Paris: Gallimard, 1997.

Prost, Antoine. Douze leçons sur l'histoire. Paris: Seuil, 2010.

RÉnAn, Ernest. Qu'est-ce quiune Nation? 1882.In: Discours et conférences. Paris: Calmann Levy, Éditeur, 1887, p. 277-310.Disponible en: <http://archive.org/ stream/questcequunenat00renagoog\#page/n9/mode/2up->. Consultado en: 3 nov. 2012. Ricœur, Paul. La memoria, la historia, el olvido. Madrid: Trotta, 2003.

Tiempo y narración I. Configuración del tiempo en el relato histórico. 5. ed. Madrid: Siglo XXI, 2004.

Si mismo como otro. Madrid: Siglo XXI, 2006.

SANDwell, Ruth (Ed.). To the past. History education, public memory and citizenship in Canada. Toronto: University of Toronto Press Incorporated, 2006.

Schleiermacher, Friedrich. Herméneutique. Ginebra: Labor/Fides, 1987. 
Spivak, Gayatri Chakravorty. ¿Puede hablar el subalterno? Orbis Tertius - Centro de Estudios de Teoría y Crítica Literaria. Facultad de Humanidades y Ciencias de la Educación ,Universidad Nacional de La Plata, Argentina, año III, n. 6, p. 175-235, 1998. Stenhouse, Laurence. La investigación como base de la ensenãnza. Madrid: Morata, 1998. Vygotsky, Lev S. Pensamiento y lenguaje. Barcelona; Buenos Aires: Paidós, 1995.

Wineburg, Sam. Historical thinking and other unnatural acts. Charting the future of teaching the past. Philadelphia: Temple University Press, 2001.

White, Hayden. La cuestión de la narrativa en la teoría historiográfica actual. In: El contenido de la forma. Narrativa, discurso y representación histórica. Barcelona: Paidós, 1992.p. 41-74.

Wittgenstein, Ludwig. De la certitude. Paris: Gallimard, 1975. . Investigaciones filosóficas. Barcelona: Atalaya, 1999.

Zamboni, Ernesta. Projeto pedagógico dos parâmetros curriculares nacionais: identidade nacional e consciência histórica. Cadernos CEDES, Campinas: CEDES, v. 23, n. 61, p. 367-377, dez. 2003.

Zavala, Ana; Scotti, Magdalena (Comps.). Historias de la enseñanza de la historia. Relatos que son... teorías. Montevideo: CLAEH, 2005.

.(Comps.).Yo enseño historia, ¿̇y usted? Una aventura hecha palabras. Montevideo: CLAEH-APHU, 2006.

Zavala, Ana. Mi clase de historia bajo la lupa. Por un abordaje clínico de la práctica de la enseñanza de la historia. Montevideo: Trilce, 2012.

\section{SOBRE LA AUTORA}

Ana Zavala es magíster en didáctica por la Universidad de Buenos Aires (Argentina). Profesora del Instituto Universitario Centro Latino Americano de Economía Humana (Uruguai).

E-mail: azavala@claeh.edu.uy

Recebido em novembro de 2012 Aprovado em março de 2013 